\title{
Ultrasonic Measurement of Two-Dimensional Liquid Velocity Profile Using Two-Element Transducer
}

\author{
Hiroshige Kikura$^{1}$, Naruki Shoji ${ }^{1}$, Hideharu Takahashi ${ }^{1}$, Wongsakorn Wongsaroj ${ }^{2}$ \\ ${ }^{1}$ Laboratory for Zero-Carbon Energy, Tokyo Institute of Technology, Tokyo, Japan \\ ${ }^{2}$ Department of Instrumentation and Electronics Engineering, King Mongkut's University of Technology North Bangkok, \\ Bangkok, Thailand \\ Email: shoji@us.nr.titech.ac.jp
}

How to cite this paper: Kikura, H., Shoji, N., Takahashi, H. and Wongsaroj, W. (2022) Ultrasonic Measurement of Two-Dimensional Liquid Velocity Profile Using Two-Element Transducer. Journal of Flow Control, Measurement \& Visualization, 10, 12-31.

https://doi.org/10.4236/jfcmv.2022.101002

Received: September 2, 2021

Accepted: January 10, 2022

Published: January 13, 2022

Copyright (c) 2022 by author(s) and Scientific Research Publishing Inc. This work is licensed under the Creative Commons Attribution International License (CC BY 4.0).

http://creativecommons.org/licenses/by/4.0/

\begin{abstract}
The flow field or multidimensional velocity distribution of the coolant in fuel rod bundles of the reactor core in pressurized water reactors (PWRs) is an important parameter that is revealed through experimental investigations. This paper presents the two-dimensional (2D) velocity profile measurement using a two-element ultrasonic transducer with both elements acting as a transceiver. The size of the transducer is minimized for compactness, leading to a narrow sound field appropriate for applications in fuel rod bundle flow. Furthermore, the transducer's sound pressure is evaluated via simulations and experimental measurements. In order to confirm the ability of the ultrasonic velocity profiler (UVP) with a two-element transducer, the experimental measurement is conducted in turbulent horizontal pipe flow. The $2 \mathrm{D}$ velocity vector profile is obtained, and then the measurement in swirling flow is conducted. The $2 \mathrm{D}$ velocity profile in an axial and radial plane is obtained utilizing the UVP measurement. Lastly, the ability of the UVP to derive the $2 \mathrm{D}$ velocity profile in the narrow area of the rod bundles is demonstrated.
\end{abstract}

\section{Keywords}

Liquid, Two-Dimensional, Ultrasonic, Velocity

\section{Introduction}

Pressurized water reactors (PWRs) [1] are nuclear power plants with many operating units. It is essential to analyze the flow behavior of the coolant in fuel rod bundles in the reactor core [2]. The spacer grids support the fuel assembly and are used as an effective mixing device by attaching various flow deflectors such 
as swirling vanes. They are installed for heat transfer enhancement between the fuel rod and coolant, which relates strongly to plant safety. Velocity distribution, which has multidimensional motion, affects heat removal from the fuel to the coolant. Hence, the multidimensional velocity distribution needs to be investigated. The experimental examination of this parameter in rod bundles is a necessity. These studies have used several probing techniques such as hot wires [3] and films [4]. Although these techniques allow for the flow velocity measurement in the rod bundle, they are intrusive measurements that disturb the flow field. Laser doppler velocimetry (LDV) [5] has been applied to explore the flow velocity in the rod bundle. Nevertheless, these techniques have been limited to point measurements and cannot measure multidimensional velocities. Moreover, particle image velocimetry (PIV) [6] can visualize velocity profiles in two dimensions. The PIV requires optical access for the laser sheet and the camera to derive the two-dimensional (2D) velocity profile in the region of interest, whereas the flow field in a typical fuel bundle with spacer-grids is optically obstructed by the rods. The method cannot provide information on the full velocity profile or flow field along the flow path of rod bundles with spacer-grids. Also, this technique can measure the velocity data in the axial plane but not in the radial plane. Therefore, a measurement technique is needed to obtain a multidimensional velocity profile non-intrusively, which is functional in less transparent environments.

An ultrasonic velocity profiler (UVP) is a nonintrusive measurement device, which does not require optical access. The UVP was firstly used in the medical field. Baker [7] utilized the UVP for blood flow sensing. A one-dimensional (1D) measurement was performed, which has some limitations. The blood flow is not fully developed to have a 1D flow [8]. Therefore, a multidimensional velocity measurement is necessary. Peronneau et al. [9] proposed a single element cross beam system using two transducers as a transceiver (i.e., transmitter/receiver). This system can only obtain the $2 \mathrm{D}$ velocity at one point, and mechanical adjustment is required to measure other points. Additionally, Scabia et al. [10] developed a multiple-element cross beam system using a 128 element array transducer; two receivers measure one point, and several receivers are required to derive the velocity data from other points. Hence, the transducer system was enormous. Takeda [11] was the first to apply the UVP to measure a liquid's 1D velocity profile in fluid engineering. This technique is recognized as a powerful tool due to its nonintrusiveness and broad range of applications, including opaque liquids. It has been applied for velocity profiles measurement in several liquids such as water [12] [13], liquid metal [14], and magnetic liquid [15]. However, these applications are 1D measurements. Furthermore, Takeda and Kikura [16] examined the velocity field of mercury flow using 2D velocity mapping with multiple transducers. Hurther et al. [17] developed a three-dimensional (3D) velocity measurement device in open-channel flow using one transmitter and four receivers. Moreover, Obayashi et al. [18] proposed a 2D measurement system using only one transceiver and receiver. Batsaikhan et al. [19] developed a 
multiple-elements cross beam system using a couple of 128 -element sectorial array transducers, where velocity data are obtained at beam cross points. In addition, Hamdani et al. [20] constructed a 2D and two velocity component measurement system using an eight-element phased array transducer and applied it to pipe flow with an elbow layout [21] [22]. These measurement concepts are practical ways of visualizing the multidimensional velocity profile. However, the transducer system was oversized and impractical for experimental analysis of the flow field in PWR fuel rod bundles. Therefore, minimization of transducer size must be pursued.

This paper proposes a UVP measurement system with a two-element array transducer to measure the $2 \mathrm{D}$ velocity profile. The transducer is compact with an active diameter of approximately $5 \mathrm{~mm}$, and each element acts as a transceiver. The wave interference generated from each element can produce one main lobe or measurement volume with the appropriate beam diameter at the center between the elements. Furthermore, the sound beam has a narrow size that is compatible with our target. Only two pulsers/receivers are required for this measurement system. The development step of the transducer development is shown in Figure 1.

In order to confirm the applicability of our UVP system, the experimental measurement in fully developed and swirling flows was demonstrated. The measurement was performed to obtain the $2 \mathrm{D}$ velocity profile in the axial and radial plane. Lastly, the UVP measurement with a two-element transducer was demonstrated in order to derive a $2 \mathrm{D}$ velocity profile of the flow field in the rod bundle configuration.

\section{Measurement Technique}

\subsection{Ultrasonic Velocity Profiler Basics}

The ultrasonic velocity profiler (UVP) method is a nonintrusive measurement to obtain instantaneous fluid velocity profiles. The method does not require optical access, meaning it can function with nontransparent fluids. The technique is based on ultrasonic reflection. Figure 2(a) illustrates the UVP principle, consisting of the ultrasound transmission, echo signals, and the reconstructed velocity profile. An ultrasonic pulse is emitted repeatedly, corresponding to a pulse repetition frequency $\left(f_{\mathrm{PRF}}\right)$ from the transducer along the measurement line. Then, the echo reflected from the reflector's surface, such as from a particle, is derived from the same transducer. Several echo sequences are needed (i.e., typically 128 sequences or at least two). Doppler signal influenced by the velocity of a moving particle can be demodulated from the echo signals. The Doppler frequency $f_{D}(i)$ directly relates to the particle's velocity ( $i$ is position). Hence, the velocity of the particle at that position $V(i)$ can be computed as

$$
V(i)=\frac{c f_{D}(i)}{2 f_{0} \sin \theta},
$$


where $f_{0}$ is the basic frequency, and $\theta$ is the incident angle. If the Stokes number or the relation between small particles and liquid is less than 0.1 , the particle closely follows the liquid streamline. Then, several particles disperse in the liquid. Consequently, the velocity profile of the liquid can be obtained.

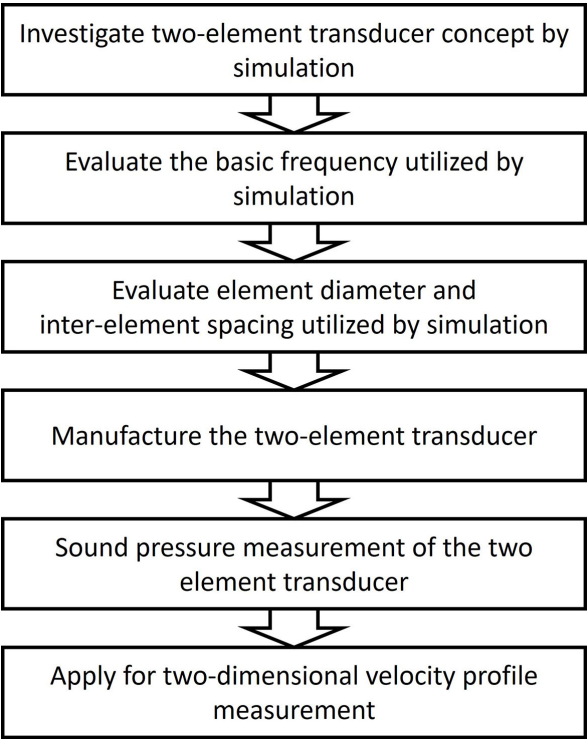

Figure 1. The development step of the transducer making.

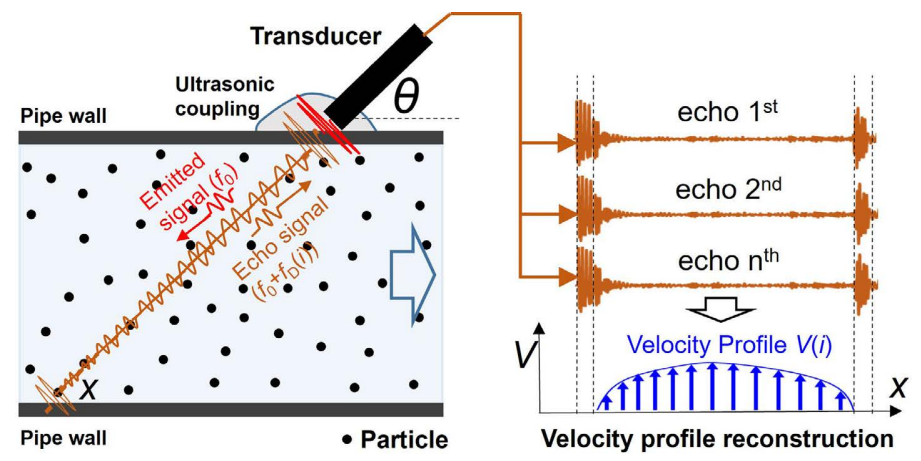

(a)

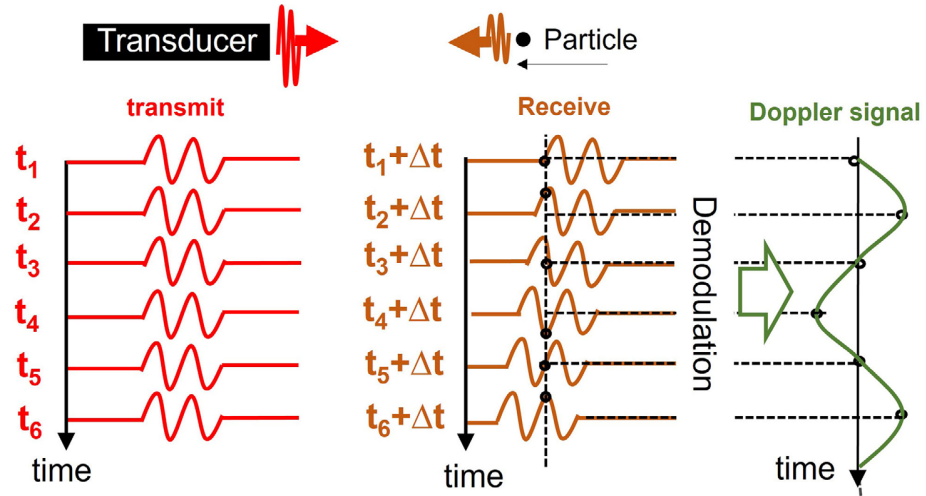

(b)

Figure 2. The UVP principle, (a) measurement configuration, (b) Doppler signal demodulation. 
In the UVP system, the Doppler pulse repetition, which is an accurate method, is used to extract the Doppler signal from the echo signals, estimate the Doppler frequency, and calculate fluid velocity, respectively. The Doppler signal can be demodulated from echo signals reflected from a moving particle, as shown in Figure 2(b). It is executed in the quadrature demodulation section. The echo signal $e(t)$ is then reflected from the particle and derived by the same transducer in [23] and is expressed as

$$
e(t)=A_{n, i} \cos 2 \pi\left(f_{0}\left(t-t_{n, i}\right)+n \frac{f_{D, i}}{f_{P R F}}\right),
$$

where $n$ is pulse repetition, $t_{n}$ represents the delay time of the echo at the $n^{\text {th }}$ pulse repetition, and $A$ is the amplitude. In the quadrature demodulation section, the echo signals are multiplied by the cosine and sine components, and a finite impulse response filter is then used as a low-pass filter to eliminate the carrier wave component or basic frequency. Therefore, the Doppler signal $D_{i}(t)$ can be extracted from the echo signals as characterized in Equation (3). The Doppler frequency is then estimated in the frequency estimation section by a frequency estimator such as autocorrelation [24].

$$
\begin{aligned}
& D_{i}(t)=\left\{2 e(t) \cos \left(2 \pi f_{0} t\right)+j \sin \left(2 \pi f_{0} t\right)\right\}_{\text {LOWPASS }} \\
& D_{i}(t)=\sum A_{n, i} \cos 2 \pi\left(\frac{f_{D, i} n}{f_{P R F}}-f_{0} t_{n, i}\right)-j \sum A_{n, i} \sin 2 \pi\left(\frac{f_{D, i} n}{f_{P R F}}-f_{0} t_{n, i}\right) \\
& D_{i}(n)=A_{n, i} \cos \left(\frac{2 \pi n f_{D, i}}{f_{P R F}}-\phi_{i}\right)-j A_{n, i} \sin \left(\frac{2 \pi n f_{D}}{f_{P R F}}-\phi_{i}\right),
\end{aligned}
$$

where $\varphi$ is the initial phase.

\subsection{UVP Measurement with Two-Element Transducer}

The UVP with a two-element transducer is proposed where the measurement mechanism is based on ultrasonic reflection. The sound wave is emitted from two ultrasonic elements, and the waves generated from each element can produce one main lobe with high acoustic intensity at the center between the elements. In addition, the echo signal reflected from moving particles is received by both elements. Then, two Doppler signals with different orientations are obtained by the receivers. The Doppler frequency in each receiver can be estimated by the autocorrelation method [24]. Hence, the 2D velocity can be reconstructed employing the following equations.

$$
\begin{aligned}
& V_{x}(i)=\frac{c}{2 f_{0}} \frac{f_{d 1}(i)+f_{d 2}(i)}{1+\cos \theta(i)}, \\
& V_{y}(i)=\frac{c}{2 f_{0}} \frac{f_{d 1}(i)-f_{d 2}(i)}{\sin \theta(i)} .
\end{aligned}
$$

Then, the velocity magnitude $(V)$ of the flow can be calculated with the equation below. The measurement concept is represented in Figure 3, and the schematic of the measurement system is illustrated in Figure 4.

$$
V(i)=\sqrt{V_{x}^{2}(i)+V_{y}^{2}(i)},
$$




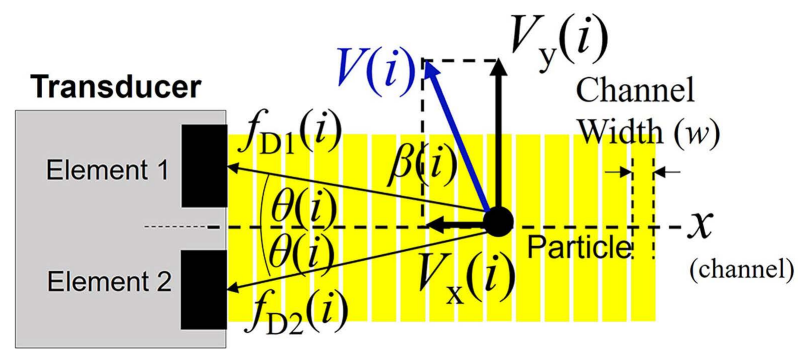

(a)

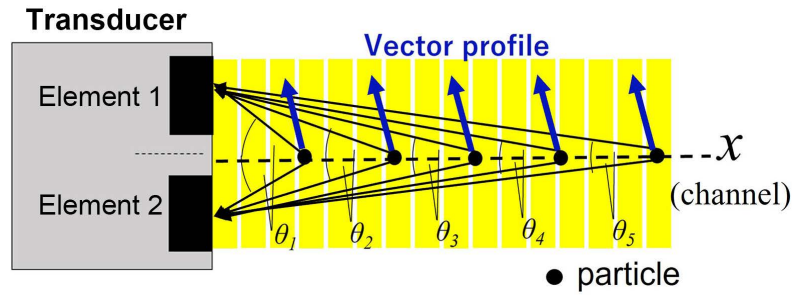

(b)

Figure 3. 2D velocity measurement.

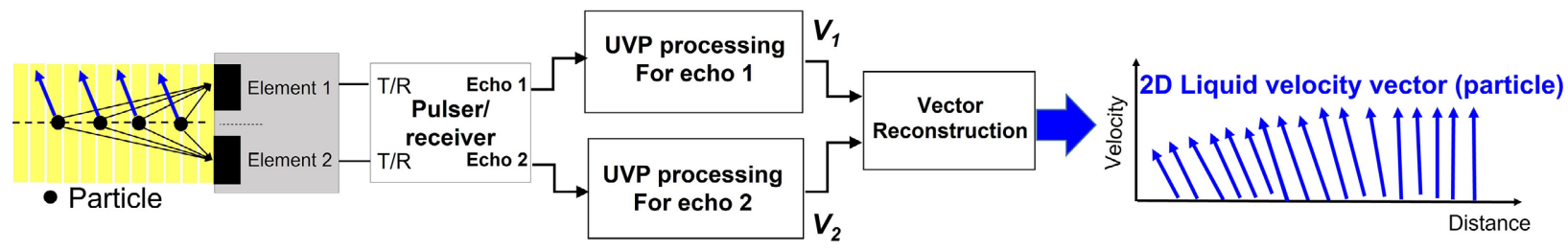

Figure 4. Schematic of the measurement system.

\section{Two-Element Transducer Design}

\subsection{Preliminary Consideration of Design}

A compact two-element concept is proposed. However, it does not simply succeed using two transducers transmitting together. For instance, if two transducers (i.e., frequency of $4 \mathrm{MHz}$ and diameter of $5 \mathrm{~mm}$ ) are attached with a pitch of $8 \mathrm{~mm}$ and transmit together simultaneously, two main lobes or measurement volumes are observed, and the $2 \mathrm{D}$ velocity measurement is not applicable, as shown in Figure 5. However, the design target for efficient measurements is one main lobe with excellent intensity and directivity with an acceptable near-field length. Therefore, the parametric study on the transducer design is the first step that has to be executed. The parameters of concern consist of the basic frequency $\left(f_{0}\right)$, element width $(a)$, and interelement spacing $(d)$, as illustrated in Figure 6. These parameters decide the measurement quality and whether we achieve the design target. Firstly, the basic frequency (i.e., 2, 4, and $8 \mathrm{MHz}$ ) is considered a candidate because its wavelength has a superior response on echo scattering reflected from the small particle dispersed in the liquid. Also, sound intensity and attenuation are within an acceptable range. Secondly, the interelement spacing (d) and element width have to be optimized. Therefore, the design parameters are selected for the best configuration to optimize measurements in the next section. 


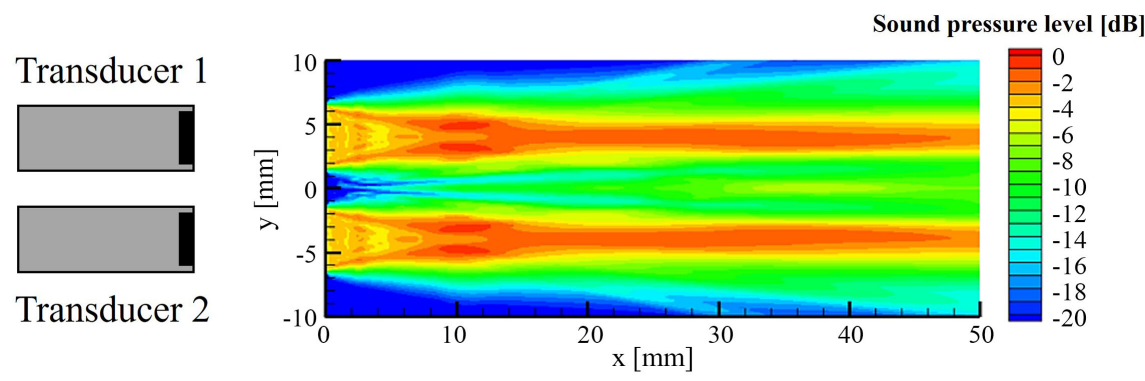

Figure 5. Simulation result of sound pressure of two transducers.

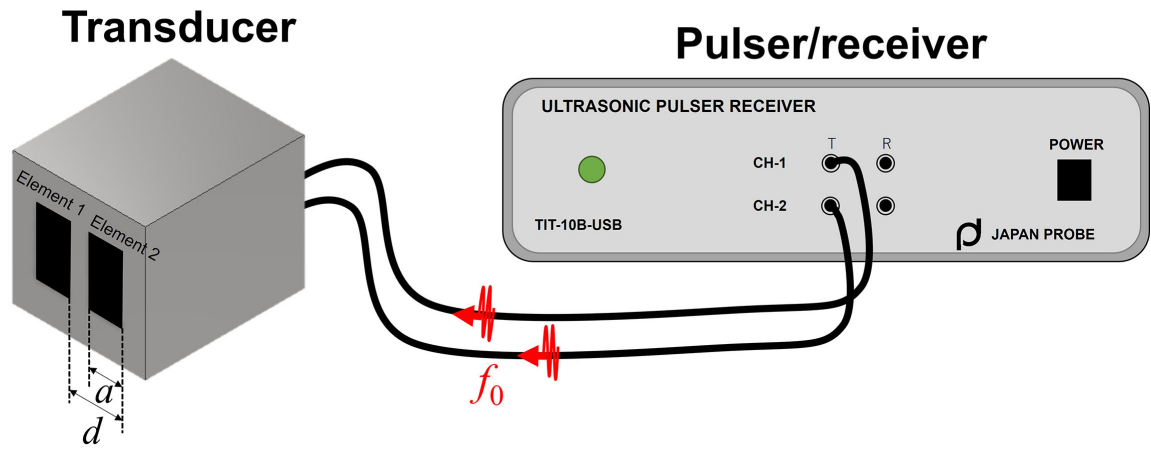

Figure 6. Schematic of the transducer and designed parameters.

\subsection{Simulation Result, Parameter Selection, and Transducer Development}

Figure 7 displays the simulation result of the sound pressure distribution at each basic frequency (i.e., 2, 4, and $8 \mathrm{MHz}$ ). The single element transducer concept with an active diameter of $5 \mathrm{~mm}$ was used as the simulation configuration. Furthermore, the intensity, directivity, and near field range were illustrated, respectively. The basic frequency at $4 \mathrm{MHz}$ attained an excellent intensity and directivity while having an acceptable near-field length. A basic frequency $f_{0}$ of $4 \mathrm{MHz}$, element width a of $2.5 \mathrm{~mm}$, and an internal element spacing $d$ of $2.7 \mathrm{~mm}$ were selected and employed to prove the performance of the design through the parametric study and sound pressure simulation using MATLAB code software. Figure 8(a) shows the simulation results at a basic frequency of $4 \mathrm{MHz}$. The design configuration described was compared with a single element with an active diameter of $5 \mathrm{~mm}$. Consequently, the transducer designed can generate one main lobe in the center between both elements. In addition, a good agreement is observed with single element transducers design. Based on the simulation data, the transducer design for 2D velocity profile measurement was reliable and was utilized to manufacture the actual transducer, as shown in Figure 8(b). In the next section, the sound pressure distribution needs to be confirmed via experiments before using the transducer for measuring the $2 \mathrm{D}$ velocity profile.

\subsection{Sound Pressure Measurement}

Sound pressure measurements were conducted in water to validate the simulation data and prove the sound field distribution of the manufactured transducer. 


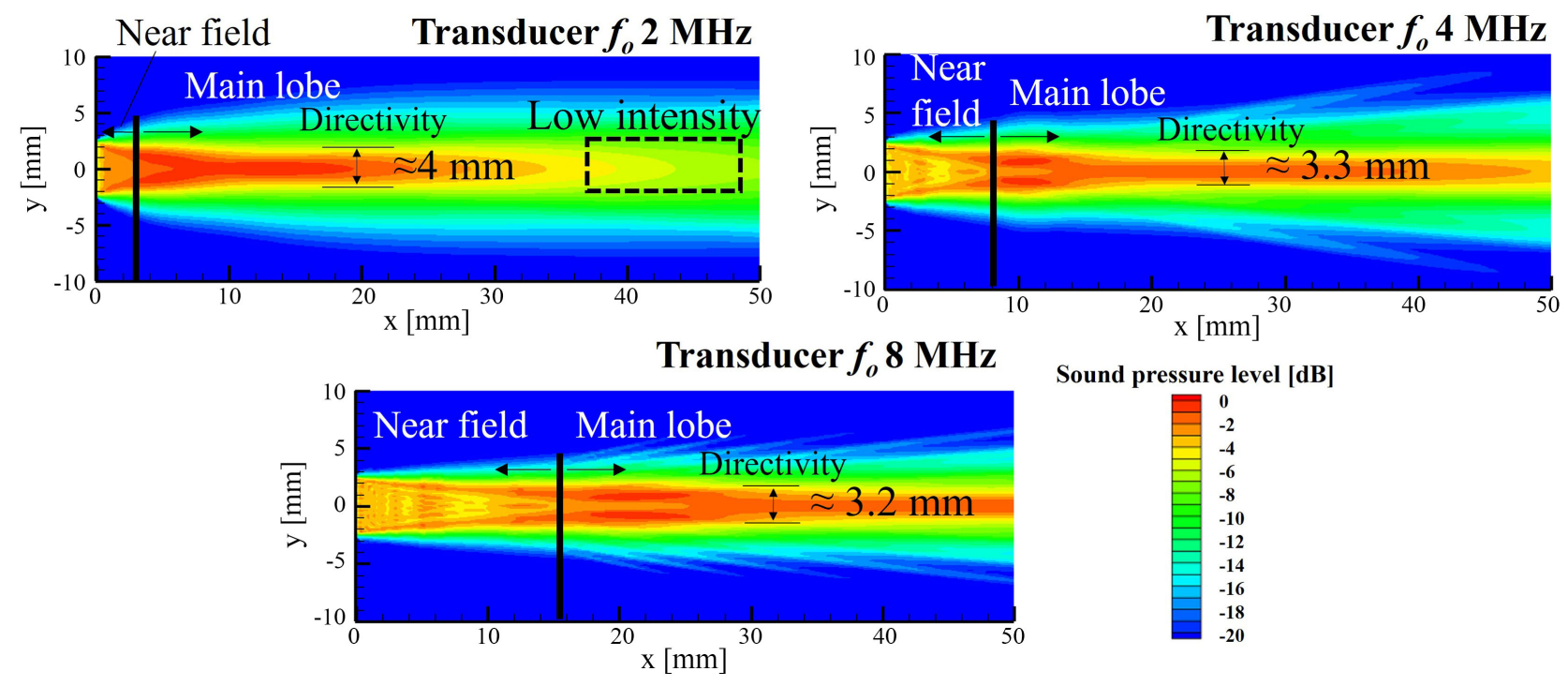

Figure 7. Simulation data sound pressure at each basic frequency.

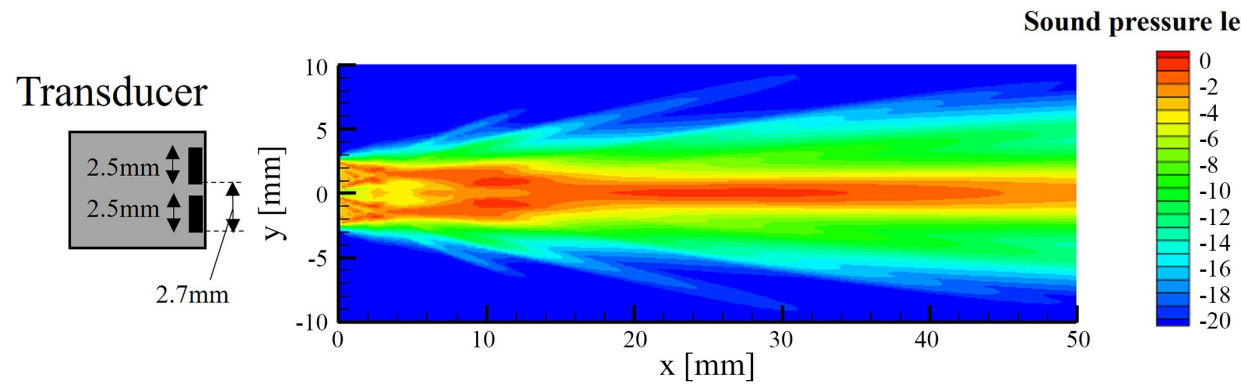

(a)

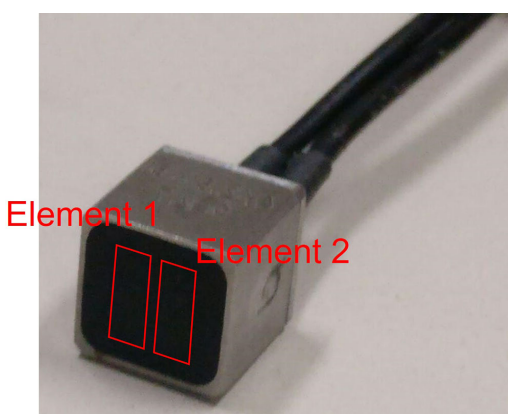

(b)

Figure 8. Simulation data of sound pressure in the two-element transducer and real transducer image.

The two-element transducer transmitted the ultrasonic pulse while the needle hydrophone functioned as a receiver to derive the pulse. Figure 9 displays the experimental setup. The transducer was controlled by a two-channel pulser/receiver (Japan Probe TIT-10B-USB). Moreover, the needle hydrophone was mounted at the XYZ stage controller, and connected to the A/D converter and PC, respectively. The needle hydrophone moved automatically, and the sound pressure measurement can be executed in a particular grid and positions in $2 \mathrm{D}$ by controlling the stage controller. In the experiment, the water temperature was 


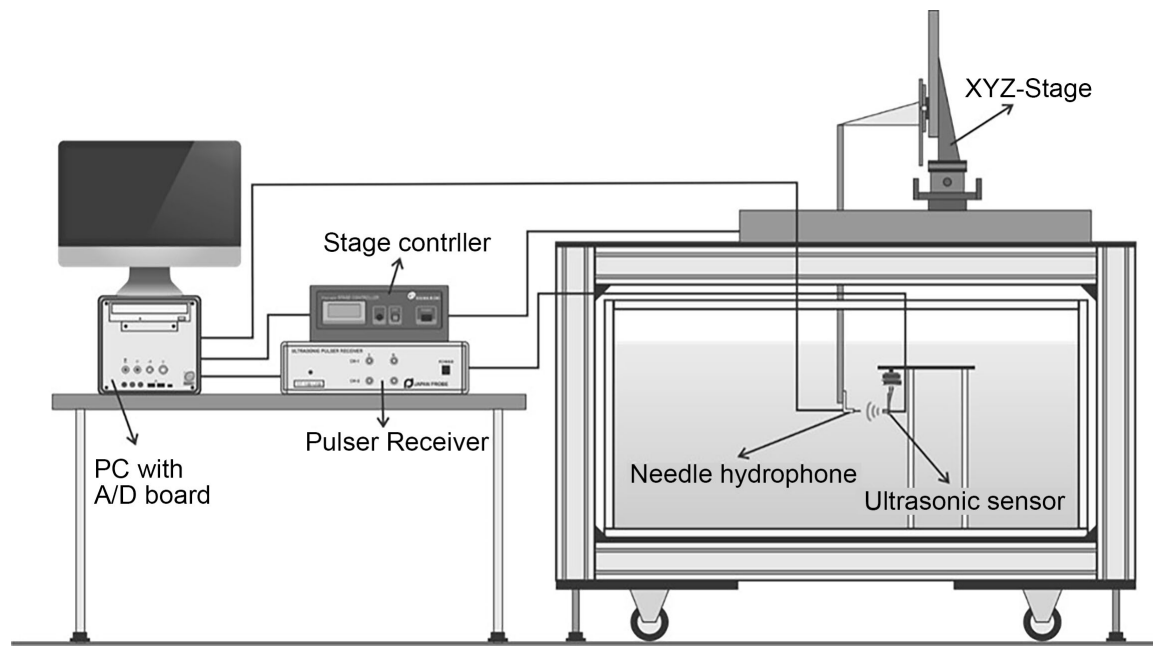

Figure 9. Apparatus for sound pressure measurement.

controlled at $23.7^{\circ} \mathrm{C}$, the axial distance $x$ was $50 \mathrm{~mm}$, the half lateral distance $y$ was $10 \mathrm{~mm}$, and the axial $\Delta x$ and lateral $\Delta y$ resolution were defined as $1 \mathrm{~mm}$ and $0.5 \mathrm{~mm}$, respectively. The signal transmitted from the transducer was recorded by needle hydrophone in sound intensity $(I)$, which is a peak-to-peak voltage. Then, the data were plotted on a color graph after being converted into the sound pressure level (SPL) using the equation below.

$$
\mathrm{SPL}=20 \log _{10} \frac{I}{I_{\max }} .
$$

The sound pressure measurement was initially performed one by one to check each element's performance and then tested as two elements transmitting together. The result is plotted on a color graph, as shown in Figure 10. Both elements were confirmed to be functional based on the one-element transmission results. Consequently, the main lobe was in the centerline of each element. Both elements experienced sound wave interference when two elements were simultaneously transmitted, resulting in one main lobe in the center between both elements. However, the sound pressure for the two elements transmitted together in the axial distance $(x)$ up to around $8 \mathrm{~mm}$ demonstrated sound intensity fluctuations. In this region, it is suspected that the measurement volume is not focused on the center. In Figure 11, the data obtained from the experiment and simulation was extracted at an axial distance $(x)$ of 1 and $5 \mathrm{~mm}$; the two intensity peaks were observed, indicating the measurement volume was not focused on the center. Therefore, the $2 \mathrm{D}$ velocity measurement might not be effective in the region with two intensity peaks (i.e., from the transducer surface to $8 \mathrm{~mm}$ ). This region is called the near-field zone. Conversely, at an axial distance of 10, 20, and $40 \mathrm{~mm}$, the data exhibited one center peak (i.e., one measurement volume). Near the lateral and axial center distance of 8 to $50 \mathrm{~mm}$, the sound distribution revealed that the intensity was higher than $-6 \mathrm{~dB}$ (i.e., strong sound intensity); the sound wave at that zone was considered to have superior directivity and a narrow beamwidth of $\approx 5 \mathrm{~mm}$. Besides, the sound pressure data of the experiment 
and simulation at the lateral center distance were compared, as shown in Figure 12. Furthermore, the intensity at a lateral center distance of $y=0$ and along the
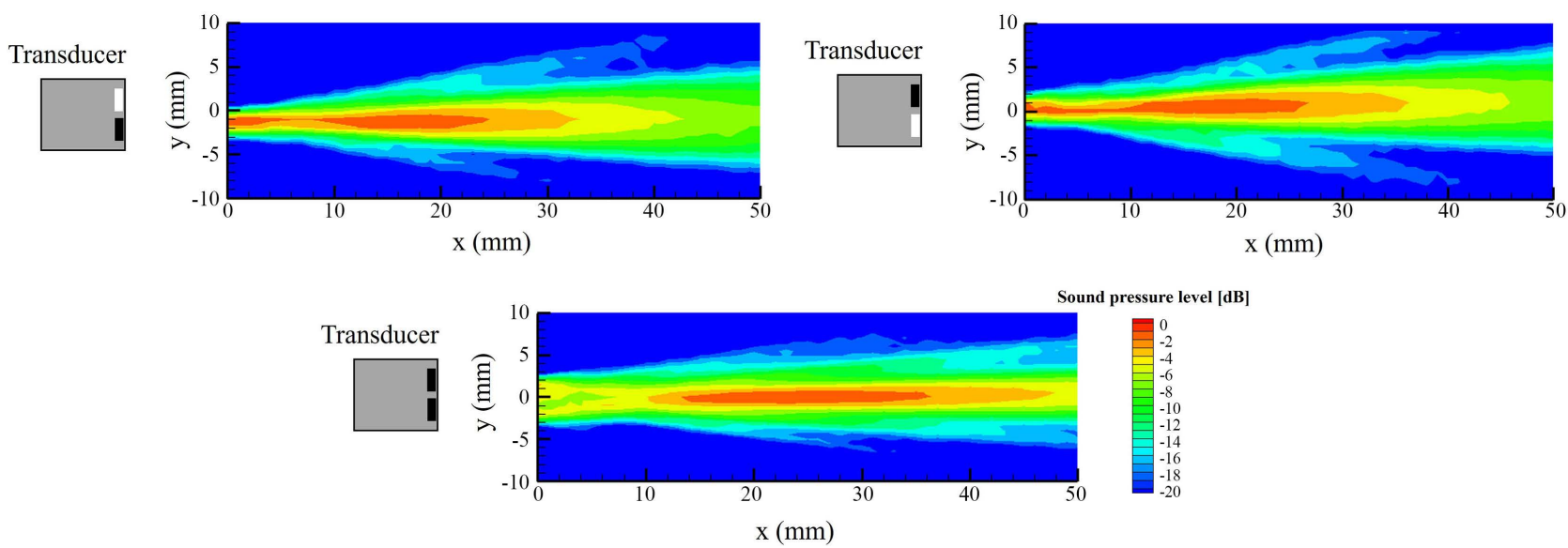

Figure 10. Sound pressure measurement of the two-element transducer.

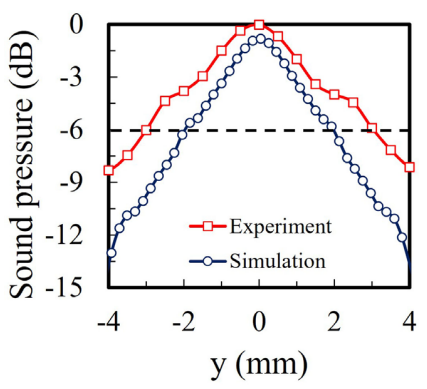

(a)

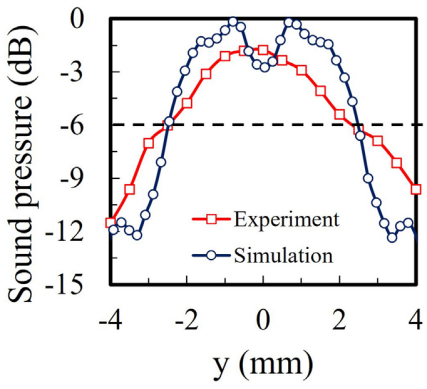

(b)

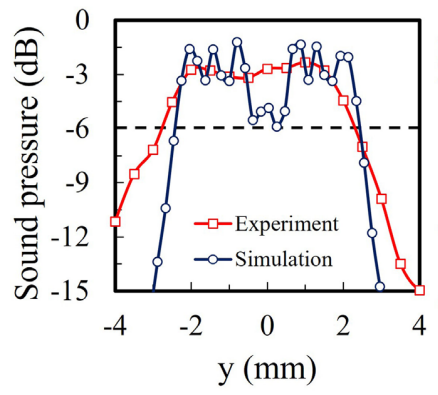

(d)

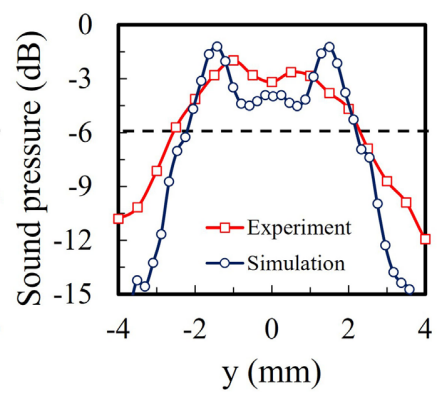

(c)

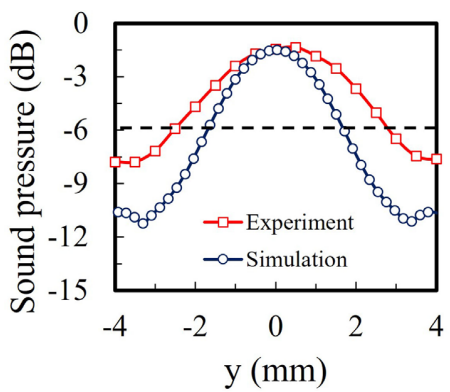

(e)

Figure 11. Normalized sound intensity along lateral distance (y), (a) $x$ $=1 \mathrm{~mm}$, (b) $x=5 \mathrm{~mm}$, (c) $x=10 \mathrm{~mm}$, (d) $x=20 \mathrm{~mm}$, (e) $x=40 \mathrm{~mm}$. 


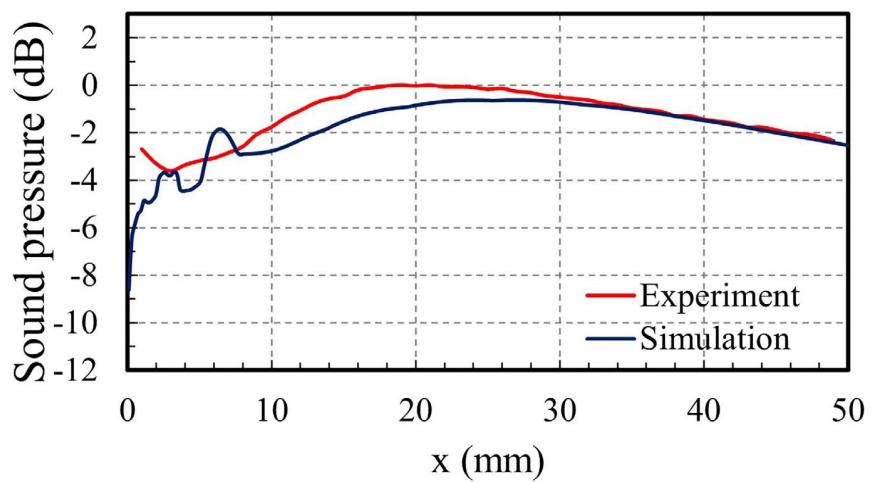

Figure 12. Normalized sound intensity at the center $(y=0)$.

axial distance was observed. The intensity obtained from simulation within the near-field zone has an oscillated form and differs from the experimental results. In the far-field zone, the simulation data intensity was higher compared to the experimental results. This difference could be due to the fact that the simulation and experiment parameters (i.e., resolution and attenuation) were not the same. Also, the dimensional uncertainty when manufacturing the transducer can cause a variation in the sound field. For instance, based on the JIS B0405-m standard and transducer dimensions, the dimensional uncertainty $\approx \pm 0.1 \mathrm{~mm}$. Overall, the sound intensity derived from the simulation and experiment has the same trend and did not significantly vary.

There is a minimal discrepancy between the simulation and experimental sound distribution results, with an acceptable near filed region, excellent directivity, and a narrow sound beam at an intensity above $-6 \mathrm{~dB}$. Therefore, we can confirm that the designed and manufactured two-element transducer can obtain $2 \mathrm{D}$ velocity profiles.

\section{2D Velocity Profile Measurement in Pipe Flow}

\subsection{Experimental Setup}

The experimental measurement was conducted to confirm the capability of measuring the $2 \mathrm{D}$ velocity. It was conducted in a horizontal acrylic pipe (inner diameter $50 \mathrm{~mm}$ ), excluding and including the swirling effect using a swirling generator (i.e., rotating pipe driven by a motor), as shown in Figure 13. The working fluid was tap water, with the temperature controlled by the cooling system. A nylon particle with a diameter of $80 \mu \mathrm{m}$ and a density similar to water $\left(1.03 \mathrm{~g} / \mathrm{cm}^{3}\right)$ was dispersed in the water and used as a reflector. The flow rate was controlled by the ball valve and was measured by an electromagnetic flow meter. Moreover, the transducer was placed in the test section, which was immersed in water as a coupling fluid to minimize the attenuation of wave propagation in the working fluid. In the UVP system, the two-element transducer was connected to the two channels pulser/receiver (Japan Probe TIT-10B-USB). An echo signal was sent to an A/D converter (National Instrument PXI-5105) connected to a PC and controlled by developed software. The experimental condition and 
measurement parameters are presented in Table 1 and Table 2. Firstly, the experiment was conducted in a fully developed flow condition, and the measurement data were plotted as velocity profiles in the axial and tangential directions. Then, the $2 \mathrm{D}$ velocity profile was reconstructed, and the axial velocity was compared with the velocity profile measured by a single element transducer. Afterward, the measurement was executed in swirling flow conditions. The $2 \mathrm{D}$ velocity profile in an axial and radial plane was derived.

Table 1. Experimental condition.

\begin{tabular}{cc}
\hline Condition & Detail \\
\hline Water temperature & $28^{\circ} \mathrm{C} \pm 1^{\circ} \mathrm{C}$ \\
Flow rate (reading) & $35 \mathrm{~L} / \mathrm{min}$ \\
Reynolds number & 18,000 \\
Pipe inner diameter & $50 \mathrm{~mm}$ \\
Motor frequency (swirling case) & $11.9 \mathrm{~Hz}$ \\
\hline
\end{tabular}

Table 2. UVP parameters.

\begin{tabular}{cc}
\hline Condition & Detail \\
\hline Basic frequency & $4 \mathrm{MHz}$ \\
Pulse repetition frequency & $1 \mathrm{kHz}$ \\
Channel width & $0.74 \mathrm{~mm}$ \\
Number of repetition & 128 \\
Voltage \& Gain & $120 \mathrm{~V}, 30 \mathrm{~dB}$ \\
\hline
\end{tabular}

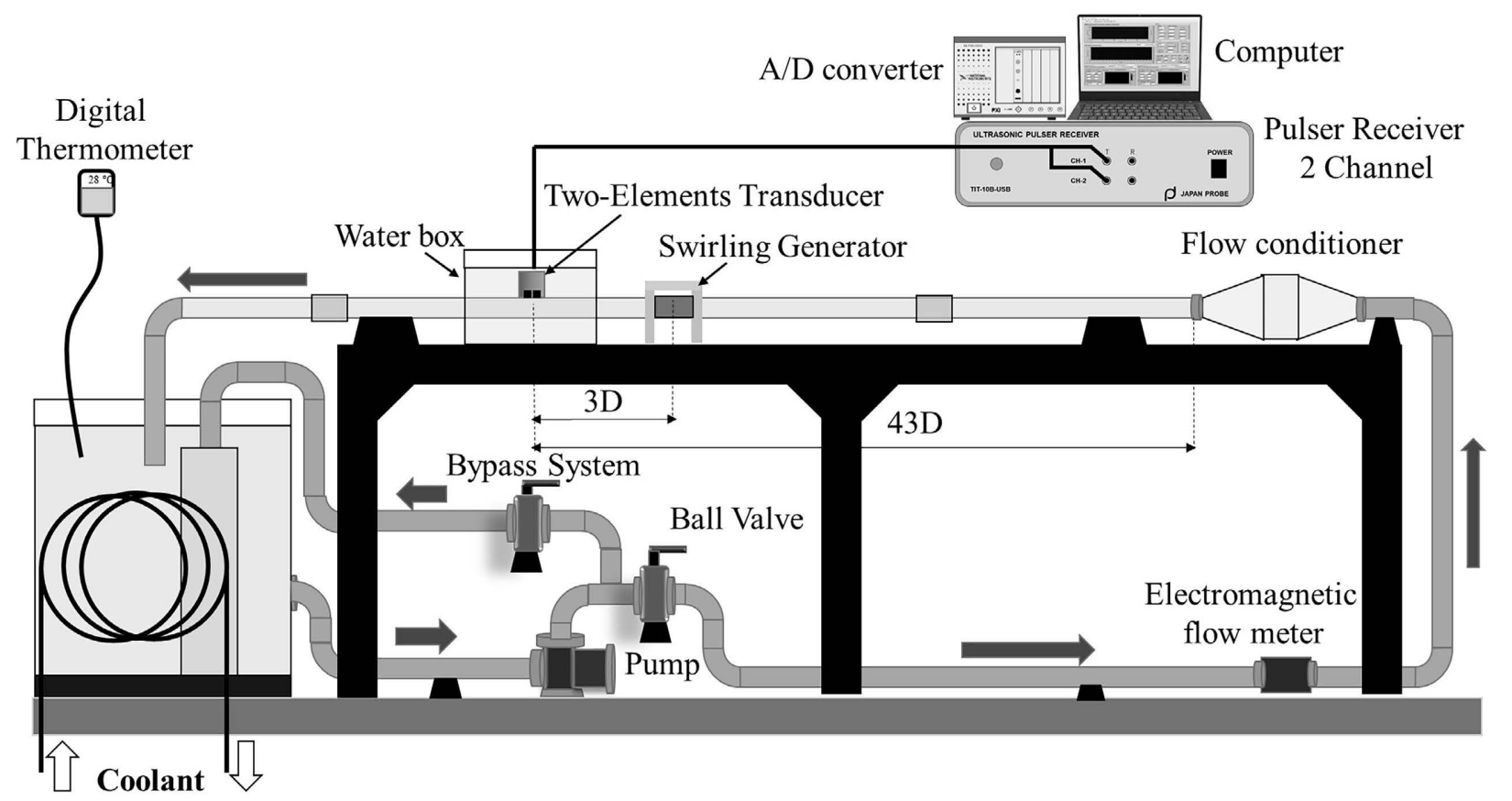

Figure 13. Pipe flow measurement apparatus. 


\subsection{Measurement and Comparison in Fully Developed Flow}

The $2 \mathrm{D}$ velocity in the turbulent pipe flow without the swirling effect was measured. The result was presented in the time-averaged velocity profile of 5000 instantaneous profiles exhibiting the axial and tangential velocities, as shown in Figure 14(a) and Figure 14(b), respectively. In this experiment, the axial direction velocity was approximately $440 \mathrm{~mm} / \mathrm{s}$ at the center of the inner pipe and about $270 \mathrm{~mm} / \mathrm{s}$ at the far wall region. The tangential velocity value was minor and had an insignificant effect on the vector reconstruction. A scattered profile was visible from the transducer surface up to around $8 \mathrm{~mm}$, which is near the field region. The sound pressure presented in the previous section was expected to be ineffective for $2 \mathrm{D}$ measurement in the near field region because the volume is not center-focused, consistent with the simulation data. Therefore, the measurement quality was reduced in this zone. In Figure 14(c), the axial velocity obtained from a two-element transducer was compared with the profile measured by a commercial $4 \mathrm{MHz}$ single-element transducer with an incident angle of 10 degrees. The comparison discrepancy was within $\pm 10 \%$ except for the near field zone and wall region, as illustrated in Figure 14(d). The statistical comparison data of average axial velocity at the center of the pipe and far pipe wall is listed in Table 3, and the report format is referred from [25]. The standard deviation and variance of the measurement at the center and far wall zone conducted by the single element transducer were relatively similar. On the other hand, the utilization of the two-element transducer, the standard deviation, and measurement variance was less than the single element results. However, these values were substantial at high measurement depths. Figure 15(a) represents the measurement result of the clearly reconstructed $2 \mathrm{D}$ velocity profile. However, the profile at the near-field region fluctuated due to the near-field effect.

\subsection{Measurement in Swirling Flow}

As described in the previous section, the realization of the $2 \mathrm{D}$ velocity profile measurement in the turbulent pipe flow is demonstrated by the swirling flow measurements where a swirling generator produced the swirling motion. It was installed at a distance upstream of the test section. The swirling effect was expected to increase the radial plane's velocity value and led to nonfully developed flow.

The measurement result was presented in a time-averaged $2 \mathrm{D}$ velocity profile, and the profile was the mean value of 5000 instantaneous profiles. Figure 15(b) presents the measurement result of the $2 \mathrm{D}$ velocity profile in an axial plane. A nonfully developed flow pattern was observed. The $2 \mathrm{D}$ velocity was derived in the radial plane, as shown in Figure 15(c), and the swirling effect was clearly captured. Nevertheless, the velocity data in the near-field zone cannot be identically measured similarly to the previous section. Overall, the two-element-based transducer design with compact geometry functions with the UVP measurement and can obtain the liquid's $2 \mathrm{D}$ velocity profile in an axial or radial plane. 
Table 3. Statistical comparison of axial velocity data.

\begin{tabular}{ccccc}
\hline Transducer concept & Location & Mean $\mathrm{mm} / \mathrm{s}$ & Std $\mathrm{mm} / \mathrm{s}$ & Variance $\mathrm{mm}^{2} / \mathrm{s}^{2}$ \\
\hline \multirow{2}{*}{ Two-element } & Center & 436.5 & 15.75 & 248 \\
& Far-wall & 268.3 & 32.76 & 1073 \\
\hline \multirow{2}{*}{ Single element } & Center & 431.3 & 21.02 & 442 \\
& Far-wall & 250.3 & 21.88 & 479 \\
\hline
\end{tabular}

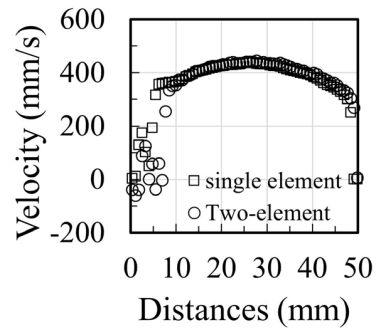

(a)

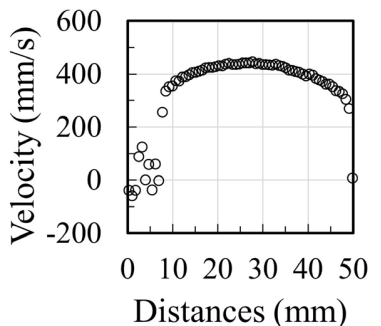

(c)

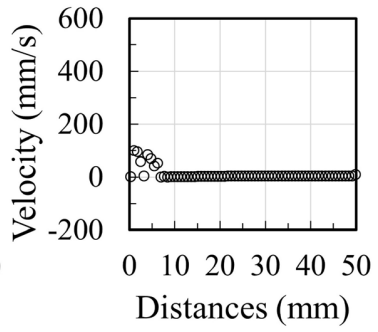

(b)

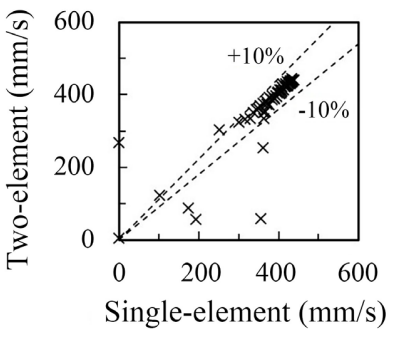

(d)

Figure 14. Velocity profile in fully developed flow, (a) axial velocity, (b) tangential velocity, (c) comparison of axial velocity, (d) the comparison discrepancy.

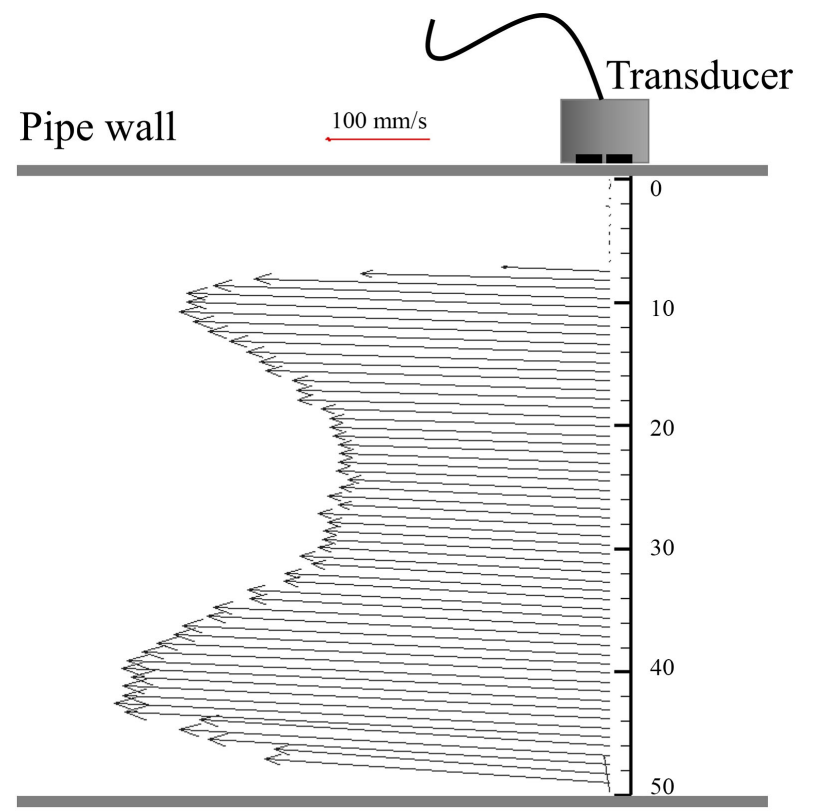

Pipe wall

(a) 


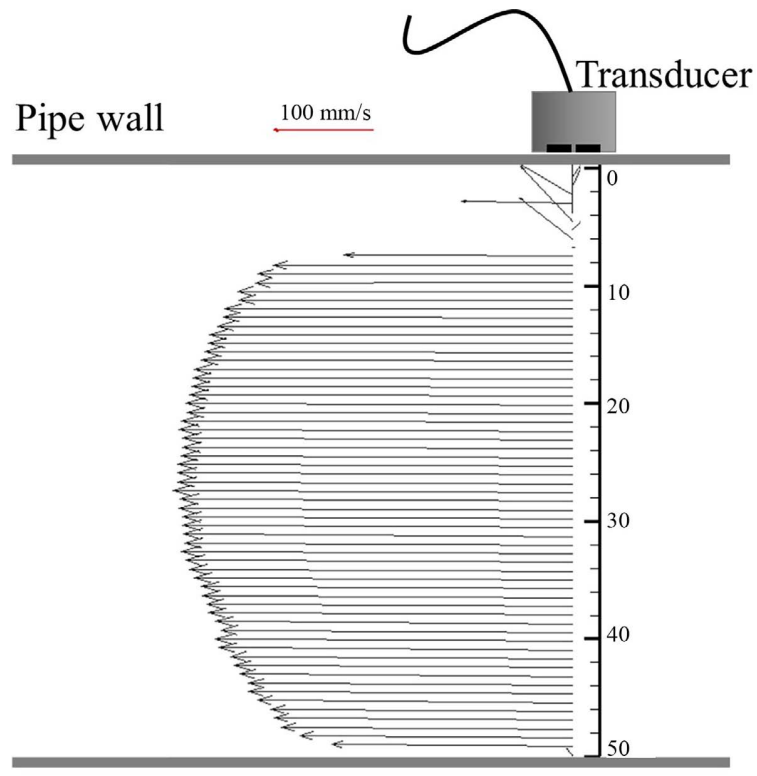

Pipe wall

(b)

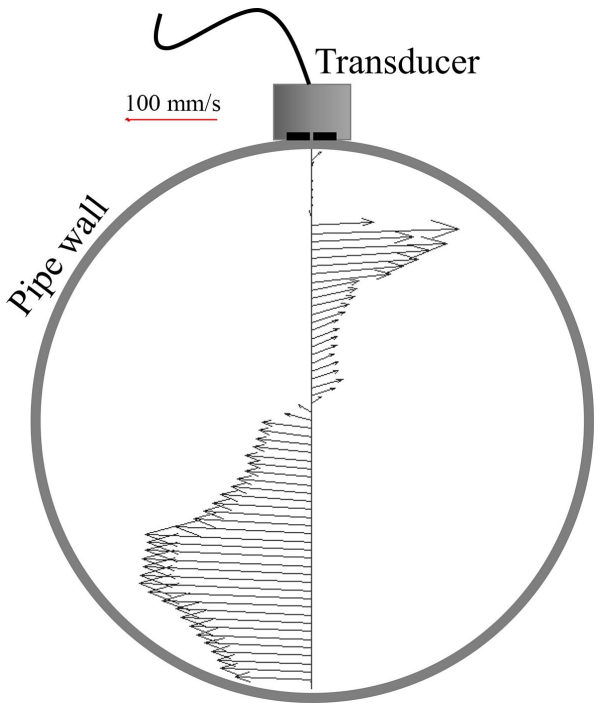

(c)

Figure 15. 2D velocity profile results for (a) axial plane in turbulent pipe flow, (b) axial plane in swirling flow, and (c) radial plane in swirling flow.

\section{2D Velocity Profile Measurement in Rod Bundle}

\subsection{Experimental Setup}

In order to achieve the target, a UVP measurement with a two-element transducer demonstration is required to investigate the flow field in rod bundles. The experiment was conducted to confirm the capability of the developed system to measure the $2 \mathrm{D}$ velocity in the narrow path of rod bundles. It was conducted in the rectangular column where four rods were used to simulate the fuel rod bundle, as shown in Figure 16. The rod diameter was $12 \mathrm{~mm}$, and the gap between 


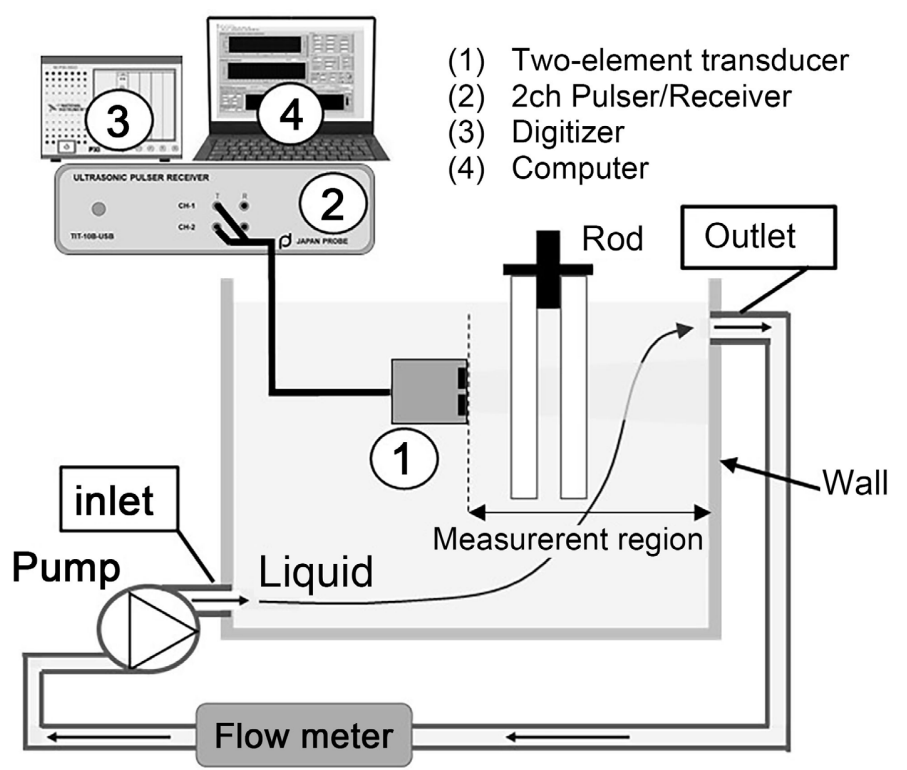

(a)

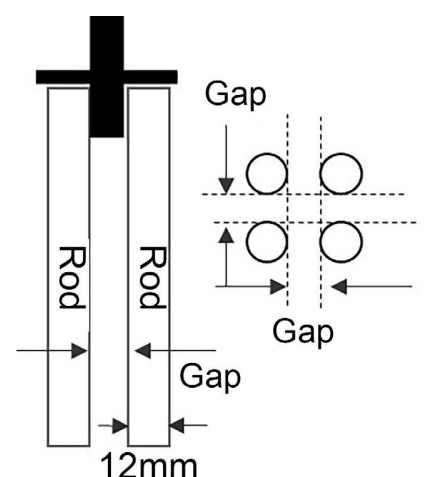

$12 \mathrm{~mm}$

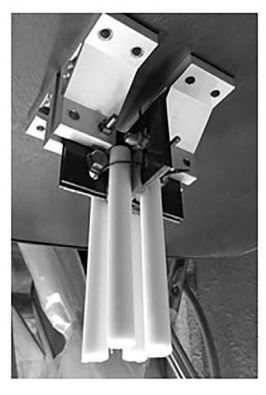

Simulation of fuel rod

(b)

Figure 16. Experimental setup for the UVP measurement in rod bundle.

the two rods was set to 8 and $3 \mathrm{~mm}$, respectively. This configuration was referred to as the experimental analysis proposed by [2] and [5].

The working fluid was tap water dispersed in nylon particles with a diameter of $80 \mu \mathrm{m}$. Additionally, a pump circulated the water from the inlet to the outlet, and the 2D flow field was formed. An impeller flow meter monitored the water flow rate, and the transducer was immersed in the water and installed at position $H=20 \mathrm{~mm}$ from the outlet center. The measurement equipment was similar to the previous experiment, and the UVP parameters were the same as in Table 2.

\subsection{Rod Bundle Measurement Results}

Figure 17 illustrates the echo signal reflected from the flow field distributed in the water column in several rod bundle configuration cases; without rods, rods installed with an $8 \mathrm{~mm}$ gap, and rods installed with a $3 \mathrm{~mm}$ gap. The echo signal in the $3 \mathrm{~m}$ gap is affected by multireflection of the rods. Alternatively, the echo signal obtained with the $8 \mathrm{~mm}$ gap prevented multireflection. The signal was 
similar to the echo signal derived in the case without rods. Figure 18 presents the measurement results of a $2 \mathrm{D}$ velocity profile derived from the flow field distributed in the rod bundles with a gap of 8 and $3 \mathrm{~mm}$, respectively; the profile corresponds to the average value of 5000 instantaneous profiles.

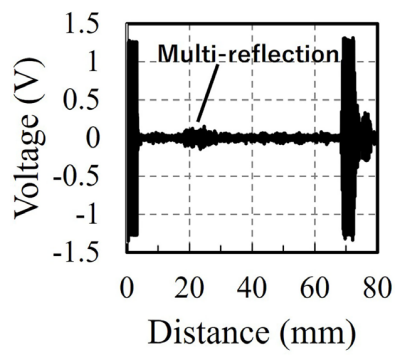

(a)

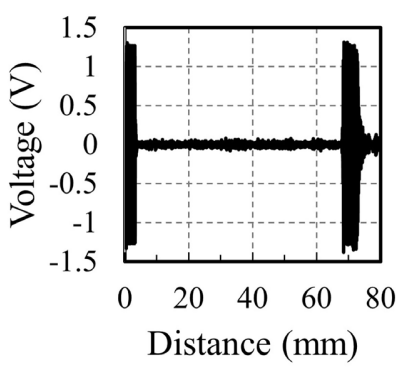

(b)

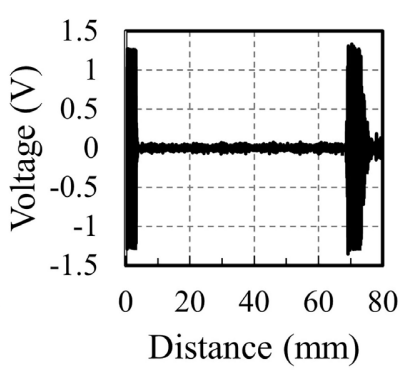

(c)

Figure 17. Echo signal, (a) without rod, (b) rods gap $=3 \mathrm{~mm}$, (c) rods with gap $=8 \mathrm{~mm}$.

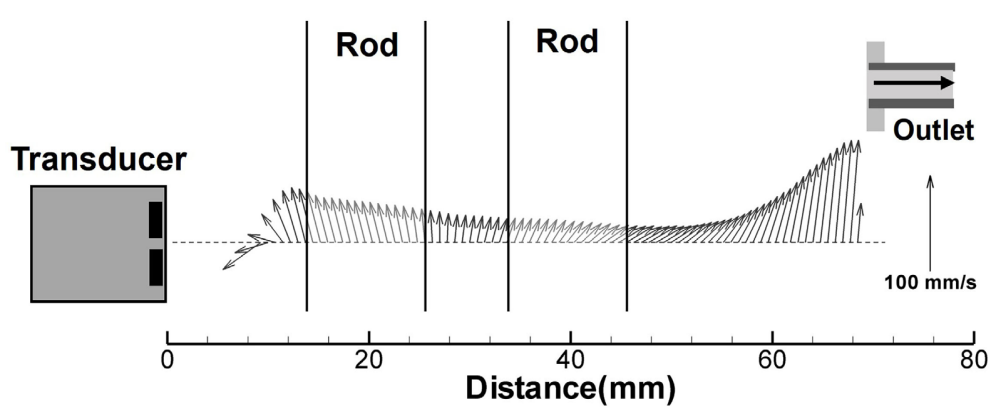

(a)

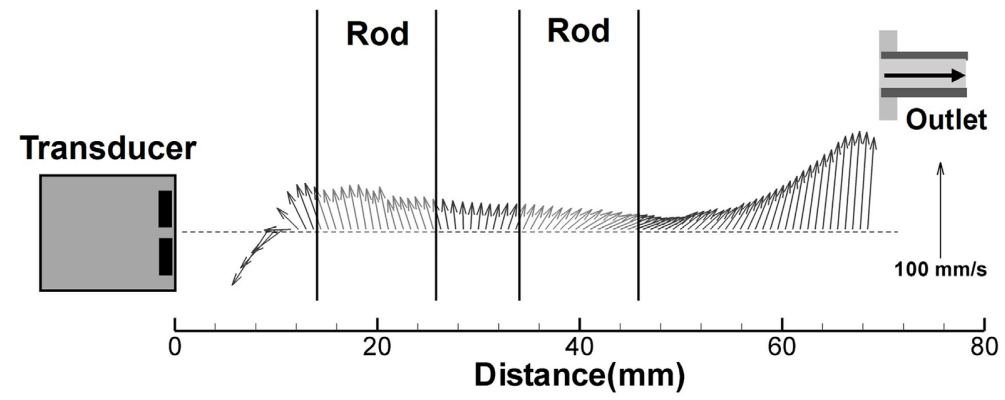

(b)

Figure 18. 2D velocity vector profile in rod bundle, (a) at gap $8 \mathrm{~mm}$, (b) at gap $3 \mathrm{~mm}$. 
In the $8 \mathrm{~mm}$ gap, the $2 \mathrm{D}$ velocity profile in the axial plane can be reconstructed, which is the path between the two rod pairs. The $2 \mathrm{D}$ velocity profile past the near-field region to the tank wall surface was obtained. The profile at a distance between 30 and $70 \mathrm{~mm}$ is directed to the outlet, indicating the reasonableness of the measurement result. Then, the gap was reduced to $3 \mathrm{~mm}$, and the $2 \mathrm{D}$ velocity profile beyond the near-field region was obtained. The effect of the multireflection was observed at $20 \mathrm{~mm}$; the profile at that point has a slight fluctuation. However, the profile of the distance behind this point until the tank wall was derived. The measured profile can visualize the flow field in $2 \mathrm{D}$ even though the gap between two rods was set to be as small as $3 \mathrm{~mm}$.

It can be concluded that the UVP measurement with a compact two-element transducer is applicable for measuring the $2 \mathrm{D}$ velocity profile of the flow field in the rod bundles.

\section{Conclusion}

This work involved the development of a compact ultrasonic transducer to function with the UVP to acquire $2 \mathrm{D}$ velocity profile measurements of liquid in narrow channels. The two-element transducer has two elements that act as a transceiver (i.e., transmitter and receiver). Moreover, the transducer was compact with an active diameter of approximately $5 \mathrm{~mm}$ to be compatible with rod bundle measurements. The basic frequency, element width, and interelement spacing were of concern for the design. The sound pressure of the designed transducer was evaluated by simulation and experiment. Furthermore, the transducer's near-field region covered $8 \mathrm{~mm}$ from its surface. Beyond the near-field region, superior directivity was observed, and the sound field distribution had an intensity higher than $-6 \mathrm{~dB}$ and beam diameter of approximately $5 \mathrm{~mm}$. The experimental demonstration was conducted in the horizontal pipe flow, and the velocity data in the axial and tangential directions were obtained. The axial velocity was validated with the velocity derived from a single transducer, and the $2 \mathrm{D}$ velocity profile in turbulent pipe flow was reconstructed. Then, the experiment in swirling flow was conducted. The 2D velocity profile in an axial and radial plane can be measured by using the UVP measurement with a designed transducer. Lastly, the proposed system's ability was applied in the narrow area similar to the fuel rod bundle. The ultrasonic wave can penetrate the liquid flow existing in the small channel. Afterward, the echo signal that carries the velocity data throughout the measurement depth can be derived, respectively. The $2 \mathrm{D}$ velocity profile in the narrow channel between the two rods can be obtained experimentally.

\section{Conflicts of Interest}

The authors declare no conflicts of interest regarding the publication of this paper.

\section{References}

[1] Masterson, R.E. (2019) Nuclear Reactor Thermal Hydraulics. Taylor \& Francis 
Group, Boca Raton. https://doi.org/10.1201/b22067

[2] Dominguez-Ontiveros, E.E. and Hassan, Y.A. (2009) Nonintrusive Experimental Investigation of Flow Behavior inside a $5 \times 5$ Rod Bundle with Spacer Grids Using PIV and MIR. Nuclear Engineering and Design, 239, 888-898. https://doi.org/10.1016/j.nucengdes.2009.01.009

[3] Rehme, K. (1987) The Structure of Turbulent Flow through Rod Bundles. Nuclear Engineering and Design, 99, 141-154. https://doi.org/10.1016/0029-5493(87)90116-6

[4] Neti, S., Eichhorn, R. and Hahn, O.J. (1983) Laser Doppler Measurements of Flow in a Rod Bundle. Nuclear Engineering and Design, 74, 105-116. https://doi.org/10.1016/0029-5493(83)90143-7

[5] Ikeda, K. and Hoshi, M. (2006) Development of Rod-Embedded Fiber LDV to Measure Velocity in Fuel Rod Bundles. Journal of Nuclear Science and Technology, 43, 150-158. https://doi.org/10.1080/18811248.2006.9711077

[6] Grant, I. (1997) Particle Image Velocimetry: A Review. Proceedings of the Institution of Mechanical Engineers, Part C: Journal of Mechanical Engineering Science, 211, 55-76. https://doi.org/10.1243/0954406971521665

[7] Baker, D.W. (1970) Pulsed Ultrasonic Doppler Blood-Flow Sensing. IEEE Transactions on Sonics and Ultrasonics, 17, 170-184. https://doi.org/10.1109/T-SU.1970.29558

[8] Dunmire, B.L., Beach, K.W., Labs, K.-H., Plett, M. and Standness Jr., D.E. (2000) Crossbeam Vector Doppler Ultrasound for Angle-Independent Velocity Measurements. Ultrasound in Medicine and Biology, 26, 1213-1235. https://doi.org/10.1016/S0301-5629(00)00287-8

[9] Peronneau, P., Sandman, W. and Xhaard, M. (1977) Blood Flow Patterns in Large Arteries. Journal of Ultrasound in Medicine B, 3, 1193-1208.

[10] Scabia, M., Calzolai, M., Capineri, L., Masotti, L. and Fort, A. (2000) A Real-Time Two-Dimensional Pulsed-Wave Doppler System. Ultrasound in Medicine and Biology, 26, 121-131. https://doi.org/10.1016/S0301-5629(99)00115-5

[11] Takeda, Y. (1986) Velocity Profile Measurement by Ultrasonic Doppler Shift Method. International Journal of Heat and Fluid Flow, 7, 313-318. https://doi.org/10.1016/0142-727X(86)90011-1

[12] Takeda, Y. (1991) Development of an Ultrasound Velocity Profile Monitor. Nuclear Engineering and Design, 126, 277-284. https://doi.org/10.1016/0029-5493(91)90117-Z

[13] Kikura, H., Yamanaka, G. and Aritomi, M. (2004) Effect of Measurement Volume Size on Turbulent Flow Measurement Using Ultrasonic Doppler Method. Experiments in Fluids, 36, 187-196. https://doi.org/10.1007/s00348-003-0694-x

[14] Kikuchi, K., Takeda, Y., Obayashi, H., Tezuka, M. and Sato, H. (2006) Measurement of LBE Flow Velocity Profile by UDVP. Journal of Nuclear Materials, 356, 273-279. https://doi.org/10.1016/j.jnucmat.2006.05.028

[15] Kikura, H., Takeda, Y. and Durst, F. (1999) Velocity Profile Measurement of the Taylor Vortex Flow of a Magnetic Fluid Using the Ultrasonic Doppler Method. $E_{X-}$ periments in Fluids, 26, 208-214. https://doi.org/10.1007/s003480050281

[16] Takeda, Y. and Kikura, H. (2002) Flow Mapping of the Mercury Flow. Experiments in Fluids, 32, 161-169. https://doi.org/10.1007/s003480100296

[17] Huther, D. and Lemmin, U. (1998) A Constant-Beam-Width Transducer for 3D Acoustic Doppler Profile Measurements in Open Channel Flows. Measurement 
Science and Technology, 9, 1706-1714. https://doi.org/10.1088/0957-0233/9/10/010

[18] Obayashi, H., Tasaka, Y., Kon, S. and Takeda, Y. (2008) Velocity Vector Profile Measurement Using Multiple Ultrasonic Transducers. Flow Measurement and Instrumentation, 19, 189-195. https://doi.org/10.1016/j.flowmeasinst.2007.11.007

[19] Batsaikhan, M., Zhang, Z.L., Takahashi, H. and Kikura, H. (2021) Development of Measurement System for Flow and Shape Using Array Ultrasonic Sensors. Journal of Flow Control, Measurement and Visualization, 9, 45-72. https://doi.org/10.4236/jfcmv.2021.93004

[20] Hamdani, A., Ihara, T. and Kikura, H. (2016) Experimental and Numerical Visualization of Swirling Flow in a Vertical Pipe. Journal of Visualization, 19, 369-382. https://doi.org/10.1007/s12650-015-0340-8

[21] Shwin, S., Hamdani, A., Takahashi, H. and Kikura, H. (2017) Experimental Investigation of Two-Dimensional Velocity on the $90^{\circ}$ Double Bend Pipe Flow Using Ultrasound Technique. World Journal of Mechanics, 7, 340-359.

https://doi.org/10.4236/wjm.2017.712026

[22] Takahashi, H., Shwin, S., Hamdani, A., Fujisawa, N. and Kikura, H. (2020 Experimental and Numerical Investigation of Swirling Flow on Triple Elbow Pipe Layout. Journal of Flow Control, Measurement and Visualization, 8, 45-62. https://doi.org/10.4236/ifcmv.2020.82003

[23] Murakawa, H., Sugimoto, K. and Takenaka, N. (2014) Effects of the Number of Pulse Repetitions and Noise on the Velocity Data from the Ultrasonic Pulsed Doppler Method with Different Algorithms. Flow Measurement and Instrumentation, 40, 9-18. https://doi.org/10.1016/j.flowmeasinst.2014.08.009

[24] Kasai, C., Namekawa, K., Koyano, A. and Omoto, R. (1985) Real-Time Two-Dimensional Blood Flow Imaging Using an Autocorrelation Technique. IEEE Transactions on Sonic and Ultrasonic, 32, 458-464. https://doi.org/10.1109/T-SU.1985.31615

[25] Burgan, H.I. and Aksoy, H. (2018) Annual Flow Duration Curve Model for Ungauged Basins. Hydrology Research, 40, 1684-1695.

https://doi.org/10.2166/nh.2018.109 